\title{
Comparative study of Pauwels type III femoral neck fractures managed by short dynamic hip screw with fibula bone graft or cannulated screws in young adults
}

\author{
Zhengqiang Li ${ }^{1 \#}$, Xuebin Zhang ${ }^{1 \#}$, Zhaowei Li $^{2}$, Aqin Peng ${ }^{1}$, Lichuang Zhang ${ }^{1}$, Yingying Deng ${ }^{1}$, \\ Lianxin Song ${ }^{1}$
}

${ }^{1}$ Trauma Emergency Center, Third Hospital of Hebei Medical University, Shijiazhuang, China; ${ }^{2}$ Trauma Orthopedics, Affiliated Hospital of Qinghai University, Xining, China

Contributions: (I) Conception and design: Z Li, L Song; (II) Administrative support: L Song; (III) Provision of study materials or patients: Z Li, L Song; (IV) Collection and assembly of data: Z Li, X Zhang, Z Li, A Peng, L Zhang, Y Deng; (V) Data analysis and interpretation: Z Li, X Zhang, Z Li, L Song; (VI) Manuscript writing: All authors; (VII) Final approval of manuscript: All authors.

\#These authors contributed equally to this work as the co-first authors.

Correspondence to: Lianxin Song. Trauma Emergency Center, Third Hospital of Hebei Medical University, No. 139 Ziqiang Road, Shijiazhuang,

China. Email: songlxwork@163.com.

Background: The aim of our study was to compare the clinical effect of short dynamic hip screw (DHS) combined with fibula bone graft and short DHS combined with cannulated screws (CS) on the treatment of femoral neck fracture in young adults.

Methods: Thirty-five Pauwels type III femoral neck fracture patients between January 2014 and May 2019 were divided into two groups: group A (patients treated with DHS combined with fibula bone graft) and group B (patient treated with DHS combined with CS). The operative time, intraoperative blood loss, fracture healing time and complication of two groups were recorded.

Results: There were no significant differences in operative time, intraoperative blood loss in two groups. Fracture healing time in group A $(5.28 \pm 1.07)$ was significantly shorter than group B $(7.31 \pm 1.65)$. The rate of fracture nonunion (0), femoral head necrosis (0) and withdrawal rate (0) in group A were significantly lower than that in group B $(4,23.5)(4,23.5)(6,35.3)(\mathrm{P}<0.01)$. Postoperative Harris function score in group A $(95.44 \pm 2.57)$ was higher than group B $(87.82 \pm 7.79)(\mathrm{P}<0.01)$.

Conclusions: DHS combined with fibula bone graft can shorten the healing time of fracture, reduce the rate of bone nonunion and femoral head necrosis, and provide a new treatment method for Pauwels type III femoral neck fracture in young adults.

Keywords: Femoral neck fracture; dynamic hip screw (DHS); cannulated screws (CS); fibula bone graft; young adults

Submitted Oct 23, 2019. Accepted for publication May 09, 2020.

doi: 10.21037/atm-19-3344

View this article at: http://dx.doi.org/10.21037/atm-19-3344

\section{Introduction}

It is estimated that the incidence of hip fractures worldwide increases to 2.6 million in 2025 (1). Femoral neck fracture is one of the most common clinical fractures, accounting for $50 \%$ of hip fractures (2). The occurrence of femoral neck fracture in young adults is usually caused by high-energy injuries such as traffic injury, fall injury and so on $(3,4)$. The Pauwels classification (5) is commonly used for femoral neck fractures in young patients.

The surgical treatment of femoral neck fracture has been developed continuously, which are often fixed with cannulated screws (CS), sliding hip screw (SHS), total 
arthroplasty (THA), dynamic hip screw (DHS) with or without antirotation screw, DHS with blade instead of screw (DHS-blade) or similar implants $(6,7)$. However, there has been no consensus for the optimal therapeutic regimen available in the literature due to the high rates of postoperative complications. Currently, DHS combined with CS is mainly used in the treatment of Pauwels type III femoral neck fracture in young adults, but $8 \%$ of patients still suffer from nonunion of bone and necrosis of femoral head (8-10).

Fibula bone graft has been recommended for the treatment of previous femoral neck fractures and has achieved good clinical results in the treatment of femoral neck fractures with nonunion and avascular necrosis of the femoral head (11). However, there are few reports on the application of fibular transplantation for the fracture of femoral neck in young adults. In this study, we introduce a novel treatment of femoral neck fracture that patients treated with DHS combined with fibular graft. Furthermore, the clinical effect of DHS combined with fibular graft in the treatment of Pauwels type III femoral neck fracture in young adults was investigated. The main objective of this study was to compare the clinical effect of short DHS combined with fibula bone graft and short DHS combined with CS on the treatment of femoral neck fracture in young adults. We present the following article in accordance with the STROBE reporting checklist (available at http://dx.doi.org/10.21037/atm-19-3344).

\section{Methods}

\section{Patients}

Thirty-five adult patients with Pauwels type III femoral neck fracture in Third Hospital of Hebei Medical University who met the inclusion criteria from January 2014 to May 2019 were retrospectively studied in this study. According to the therapeutic regimes, 18 cases were treated with DHS combined with fibula bone graft and thus defined as the group A, while 17 cases were treated with DHS combined with CS and thus defined as the group B. The surgical options were determined by the treating physician. Seven cases were caused by a fall injures and 11 cases were caused by traffic accident injuries in group A. Ten cases were caused by fall injuries and 7 cases were caused by traffic accident injuries in group B. The diagnosis and classification were assisted by the clinical examination of the injured body, the lateral X-ray of the affected hip joint,
CT and the three-dimensional reconstruction. This study was approved by the Medicine Human Experimental ethic committee of Qinghai University School and all patients signed the written informed consent.

Inclusion criteria were patients (I) with fresh closed femoral neck fracture; (II) who were aged 16-65 years; (III) with Pauwels III type femoral neck fracture (Pauwels angle $>50^{\circ}$ ) (the Pauwels angle refer to the angle between fracture line and the iliac spine line) (12); (IV) the patient had good hip movement before injury; (V) complete the follow-up. Exclusion criteria were patients (I) with ipsilateral femoral fracture; (II) with pathological fracture of femoral neck; (III) with old femoral neck fracture; (IV) open fracture; (V) disorders of consciousness, new cerebral infarction and previous hip disease.

All the patients voluntarily underwent short DHS combined with fibula bone graft or DHS combined with CS internal fixation. DHS was provided by Tianjin Zhengtian (Tianjin, China), CS was provided by Stryker (Stryker, USA), and fibula strips were all autogenous.

\section{Preoperative preparation}

After admission, routine examination and laboratory tests were performed, and relevant departments were invited to consult and treat related diseases. Preoperative imaging examination of the affected side of the hip was performed to timely understand the displacement of the fracture end. No traction was performed on the affected limb before operation. Preoperative routine preventive measurements of infection and deep venous thrombosis of lower limbs was administered. Preoperative routine drugs for pain, swelling and other symptomatic treatment was performed. There were no donor site complications including donor site fractures, skin infections, non-healing, and necrosis.

\section{Operation methods}

Both operations were performed by Professor Lianxin Song. Patients in both groups were given continuous epidural anesthesia or general anesthesia and lay on the traction bed after satisfactory anesthesia. Under the C-arm X-ray fluoroscopy, the method of Leadbetter (13) or McElvenny (14) is adopted for closed reduction. Three-dimensional interactive reduction of femoral neck can be used when the reduction was difficult (15). Garden's classification was used and the combination of anteroposterior (AP) and lateral methods were used to reset 
and restore the femoral anteversion and neck-shaft angle. The traction of the affected limb was continued. The area of routine iodine alcohol disinfection was covered with sterile towel. An approximate $8 \mathrm{~cm}$ longitudinal incision was made on the affected hip joint. The skin, subcutaneous, fascia, and lateral femoral muscle were cut layer by layer, then subtrochanteric cortex was exposed.

Under the C-arm fluoroscopy, two guide pins were drilled parallel to $1 \mathrm{~cm}$ above the femoral neck near the calcar femorale to fix the fracture of the acetabulum. After depth sounding, a step drill was used to drill holes. After tapping, a DHS of appropriate length was inserted into the subcortical femoral head for 5-10 mm. A 2-hole dynamic hip plate was placed at the distal end of the fracture and made to adhere to the bone cortex on the lateral side of the femur. Two screws were then drilled.

For group A, an incision was made in the posterolateral part of the middle and upper part of the lower leg of the ipsilateral side. The incision was separated between the gastrocnemius muscle and the peroneus brevis muscle to expose the fibula. The guide pin was drilled successively along the top with different types of hollow drills with a diameter of $14 \mathrm{~mm}$. The guide pin was pulled out and fibula strips were inserted along the bone hole. For group B, after depth sounding, a hollow nail was inserted along the upper guide pin and the guide pin was then pulled out.

When the fracture end alignment was good and the position and length of the internal fixation had no deviation under C-arm fluoroscopy, the incision should be closed after washing with normal saline.

\section{Postoperative management}

Antibiotics were routinely applied for 1 day after surgery to prevent infection. Quadriceps exercises and active plantar flexion and back extension exercises of the ankle were performed 1-2 days after surgery. Hip and knee loosening training was conducted on the 3-5 days, and hip and knee flexion $>90^{\circ}$ before discharge. Weight-bearing activities were not allowed within 4 weeks after surgery, then rehabilitation guidance of the affected limb was given to the patient according to the results of outpatient review.

\section{Follow up and outcome evaluation}

Operative time, intraoperative blood loss and fracture healing time of two groups were recorded. Fracture healing was defined as the $\mathrm{X}$-ray showing that the bone callus at the fracture breaking end of the fracture became smaller in size, dense, clear in edges, the fracture line disappeared, and trabecular bone passed across the broken ends. At the last follow-up, the Harris hip function scale was used to score hip function. Preoperative and postoperative visual analogue scale (VAS) score were recorded.

The incidence of complications in the two groups was observed and recorded during follow-up, including nail withdrawal rate, fracture nonunion and femoral head necrosis rate. Nonunion of fracture was defined as the results of reexamination indicating that there was little callus at the fracture end, a gap between the bone ends to form a pseudojoint, and no trabecular formation. The two broken ends were atrophic and smooth, and the bone marrow cavity was filled with dense bone and occluded. A vascular necrosis of the femoral head presents on imaging as subchondral sclerosis or segmental collapse.

\section{Statistical analysis}

Statistical analyses were conducted using SPSS, version 23.0 (SPSS, Inc., Chicago, IL, USA). The nail withdrawal rate, fracture nonunion rate, femoral head necrosis rate and other count data were expressed as percentage (\%) and were analyzed by Chi-square test. Operation time, intraoperative blood loss, fracture healing time, preoperative Harris score and postoperative VAS score were expressed as means and standard deviation, and were analyzed by paired samples $t$-test. A $\mathrm{P}<0.05$ was considered statistically significant.

\section{Results}

\section{Baseline characteristics}

There were no significant differences in the baseline information between the two groups including age, gender, injury mechanism, side, Garden type, Pauwels angle and time from injury to surgery (Table 1).

\section{Surgical outcomes}

All postoperative incision of two groups got stage I healing. Operation time and intraoperative blood loss in two groups were not statistically significant $(\mathrm{P}=0.848 ; \mathrm{P}=0.887)$. Fracture healing time of group A was significantly shorter than group $\mathrm{B}(\mathrm{P}<0.01)$. VAS scores of the two groups before and after surgery between two groups showed no statistical significance $(\mathrm{P}=0.424 ; \mathrm{P}=0.713)$ (Table 2). 


\section{Page 4 of 8}

\section{Follow-up outcomes and complications}

The follow-up time of group A were $20 \pm 5.1$ months and the follow-up time of group B were $26 \pm 6.6$ months. The main complications in this study were fracture nonunion, femoral head necrosis and nail withdrawal rate. The rate of fracture nonunion, femoral head necrosis and nail withdrawal rate in group A was significant lower than that in group $\mathrm{B}(\mathrm{P}=0.029 ; \mathrm{P}=0.029 ; \mathrm{P}=0.006)$ (Table 3). At the last follow-up, the Harris scores of group A was significant higher than group $\mathrm{B}(\mathrm{P}<0.05)$ (Table 2). Typical cases are shown in Figures 1 and 2.

Table 1 Demographics and characteristics of patients

\begin{tabular}{lcc}
\hline Group & $\begin{array}{c}\text { Group A } \\
(\mathrm{n}=18, \%)\end{array}$ & $\begin{array}{c}\text { Group B } \\
(\mathrm{n}=17, \%)\end{array}$ \\
\hline Age (year, mean $\pm \mathrm{SD})$ & $44.17 \pm 10.80$ & $45.12 \pm 14.22$ \\
Gender & $5(27.78 \%)$ & $8(47.06 \%)$ \\
Female & $13(72.22 \%)$ & $9(52.94 \%)$ \\
Male & $7(38.89 \%)$ & $10(58.82 \%)$ \\
Injury mechanism & $11(61.11 \%)$ & $7(41.18 \%)$ \\
Fall injury & & \\
Traffic accident injuries & $9(50.00 \%)$ & $7(41.18 \%)$ \\
Side & $9(50.00 \%)$ & $10(58.82 \%)$ \\
Left & & \\
Right & & $13(76.47 \%)$ \\
Garden type & $10(55.56 \%)$ & $4(23.53 \%)$ \\
Type III & $8(44.44 \%)$ & \\
Type IV (with comminuted \\
posterior wall)
\end{tabular}

\section{Discussion}

In this study, DHS combined with fibula graft in young adults Pauwels type III femoral neck fracture had a high Harris function score, better bone healing and lower complications of femoral head necrosis with good the hip joint function outcomes compared to patients treated with the DHS combined with CS.

Femoral neck fractures occur most often in the elderly and are generally caused by low energy injuries, while femoral neck fractures in young adults are usually caused by high energy injuries (16). Young adults with Pauwels type III fractures are caused by severe soft tissue injury due to high-energy violence, poor biological environment and serious damage to blood supply of femoral head, resulting in a bone nonunion rate and necrosis rate up to $33 \%(17,18)$.

In clinical practice, DHS is often used for the treatment of young Pauwels type III fractures, which is designed in accordance with the anatomical and biomechanical principles of proximal femur (19). In order to obtain stronger fixation and anti-rotation, most experts suggest adding a CS to increase the rotation-resistance of the main dynamic hip nail, thus reducing the incidence of nail withdrawal rate and cutting-out of the internal fixation instruments (20). Li et al. had reported that CS with deep circumflex iliac artery bone grafting is a feasible and effective method in the treatment of young adult patients with femoral neck (21). Although deep circumflex iliac artery bone grafting can achieve good treatment results in most cases, however it is highly technical and requires microsurgical facilities and experience which limits its clinical application. In addition, it is mostly used in treating old femoral neck fractures. Makki et al. found that compared with the pure use of DHS, DHS combined with CS in a certain extent can provide further fixation, but it does not help to promote fracture healing and reduce the incidence of femoral head necrosis (22). Furthermore, although the

Table 2 Comparison of general condition in two groups (mean \pm SD)

\begin{tabular}{|c|c|c|c|c|c|c|}
\hline Groups & $\begin{array}{l}\text { Operation } \\
\text { time (h) }\end{array}$ & $\begin{array}{c}\text { Intraoperative blood } \\
\text { loss }(\mathrm{mL})\end{array}$ & $\begin{array}{c}\text { Fracture healing } \\
\text { time (min) }\end{array}$ & Harris score & $\begin{array}{c}\text { Preoperative VAS } \\
\text { score }\end{array}$ & $\begin{array}{l}\text { Postoperative } \\
\text { VAS score }\end{array}$ \\
\hline Group A $(n=18)$ & $3.25 \pm 1.23$ & $372.22 \pm 244.48$ & $5.28 \pm 1.07$ & $95.44 \pm 2.57$ & $6.83 \pm 1.09$ & $3.22 \pm 0.81$ \\
\hline $\mathrm{t}$ & 0.194 & 0.143 & -4.15 & 3.93 & 0.809 & 0.371 \\
\hline$P$ & 0.848 & 0.887 & 0.00 & 0.00 & 0.424 & 0.713 \\
\hline
\end{tabular}

VAS, visual analogue scale. 
fractures were fixed by internal fixation, the fractures are still prone to redisplace due to the defect in the posterior lateral wall $(22,23)$. Banks et al. found that the nonunion rate in comminuted posterior lateral femoral neck was as high as $60 \%$ (24). After long-term follow-up of 61 patients with Pauwels type III femoral neck fracture, van Embden et al. found that the nonunion rate of DHS fixation was about $8 \%$ (10). In this study, the nonunion rate and femoral head necrosis rate of group B were $23.5 \%$ and $23.5 \%$, which were consistent with the literature report that the combination of

Table 3 Comparison of postoperative complications between the two groups

\begin{tabular}{lccc}
\hline Group & $\begin{array}{c}\text { Fracture } \\
\text { nonunion }(\mathrm{n}, \%)\end{array}$ & $\begin{array}{c}\text { Femoral head } \\
\text { necrosis }(\mathrm{n}, \%)\end{array}$ & $\begin{array}{c}\text { Nail removal } \\
(\mathrm{n}, \%)\end{array}$ \\
\hline $\begin{array}{l}\text { Group A } \\
(\mathrm{n}=18)\end{array}$ & $0(0)$ & $0(0)$ & $0(0)$ \\
$\begin{array}{l}\text { Group B } \\
(\mathrm{n}=17)\end{array}$ & $4(23.5)$ & $4(23.5)$ & $6(35.3)$ \\
$\chi^{2}$ & 4.78 & 4.78 & 7.68 \\
$P$ & 0.029 & 0.029 & 0.006 \\
\hline
\end{tabular}

DHS and CS would cause serious complications.

Mechanical stability and good biological environment are equally important in the healing process of femoral neck fractures (25). Inclan et al. reported that ischemic femoral head underwent revascularization after allograft, and various bone grafts were applied to achieve fracture healing and femoral head revascularization (26). Currently, common bone grafts include ilium graft, muscle-pedicle graft and vascularized bone flap graft (27-29). Previous literatures had reported that free fibula bone graft has achieved good results in the treatment of fresh femoral neck fractures $(23,30)$. In this study, free fibula bone was used to replace CS. In this study, the nonunion rate of femoral head in group A were both $0 \%$, which were lower than previous studies, reporting that CS combined with fibular graft for the treatment of femur neck fracture in young adults $(31,32)$.

As biodegradable grafts, the free fibula ends up fusing with the neck of the femur rather than absorbing, so it does not loosen (33). Fibula graft retained the advantages of DHS combined with CS, the donor site morbidity will be minimized as long as enough attention was given. The implant technique is easy to operate and does not require professional microsurgical knowledge (34). In this study, the
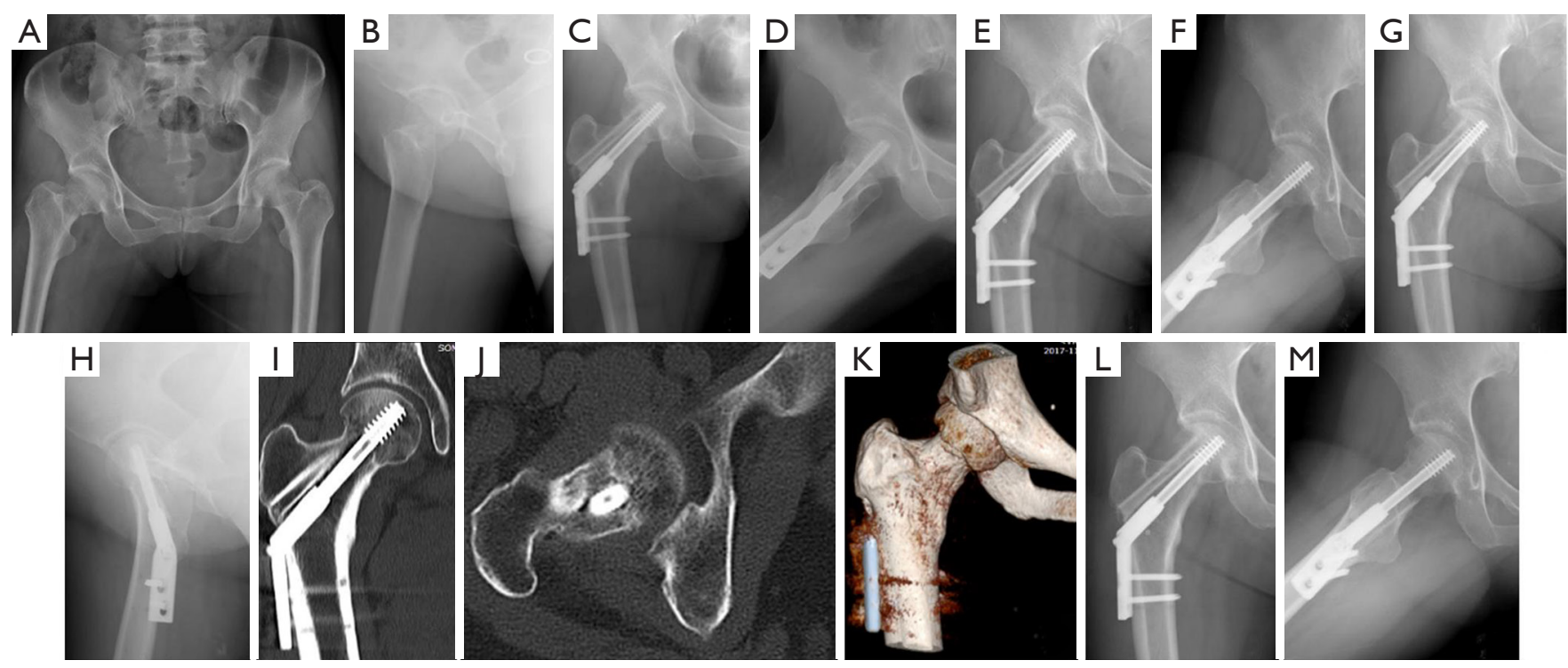

Figure 1 A 40-year-old female patient with right femoral neck fracture was treated with DHS combined with fibula bone grafting. (A,B) Preoperative positive and lateral X-ray of the hip joint showed a fracture of the right femoral neck; (C,D) postoperative positive and lateral $\mathrm{X}$-ray of the hip joint showed the internal fixator was present and well positioned; (E,F) 4 months after the operation, positive and lateral X-ray of the hip joint showed that the fracture had healed and the internal fixation was good; $(\mathrm{G}, \mathrm{H}, \mathrm{I}, \mathrm{J}, \mathrm{K}) 8$ months after the operation, positive, lateral X-ray and CT of the hip joint showed that the fracture has healed and the internal fixation is good; (L,M) 15 months after the operation, positive and lateral X-ray of the hip joint showed that the fracture has healed and the internal fixation is good. 

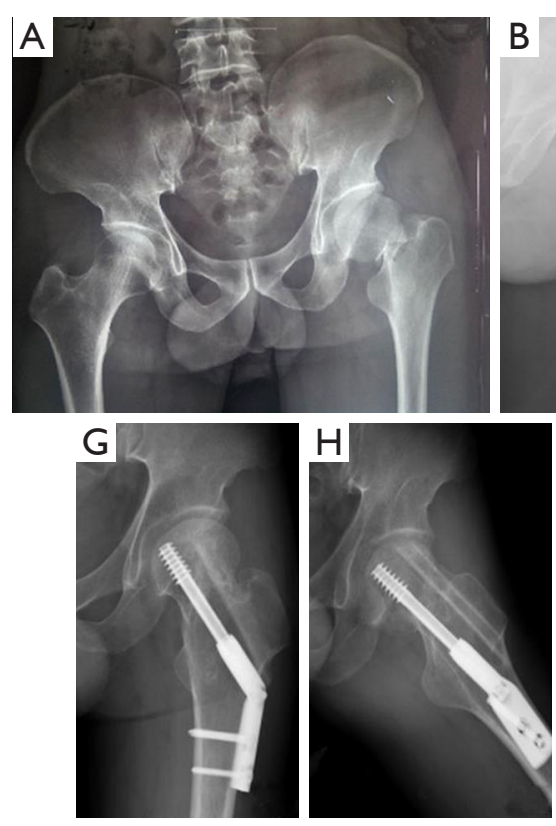
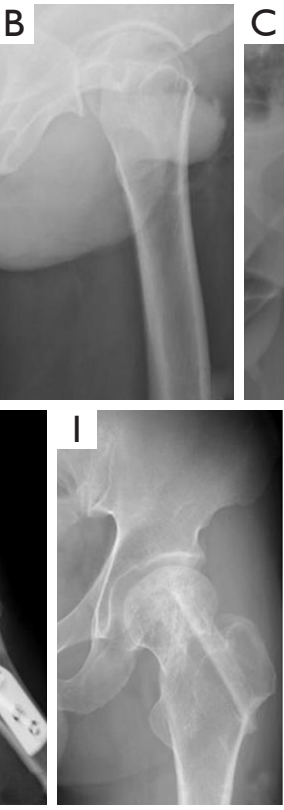
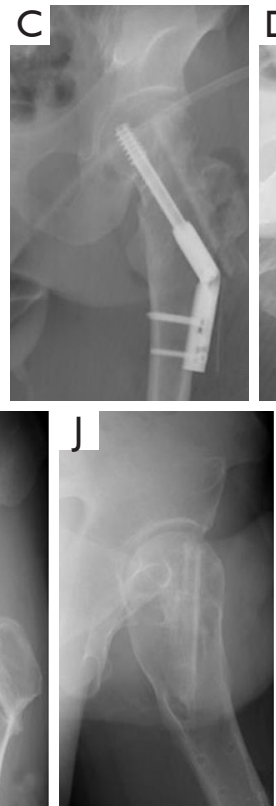
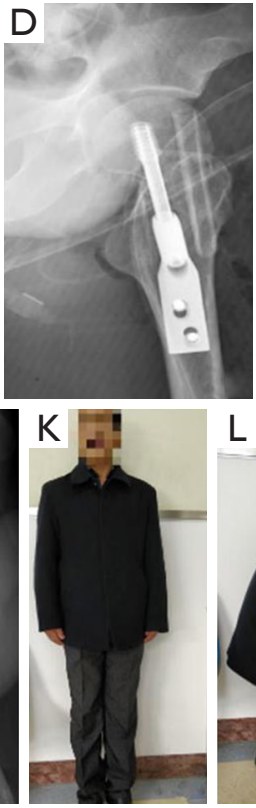
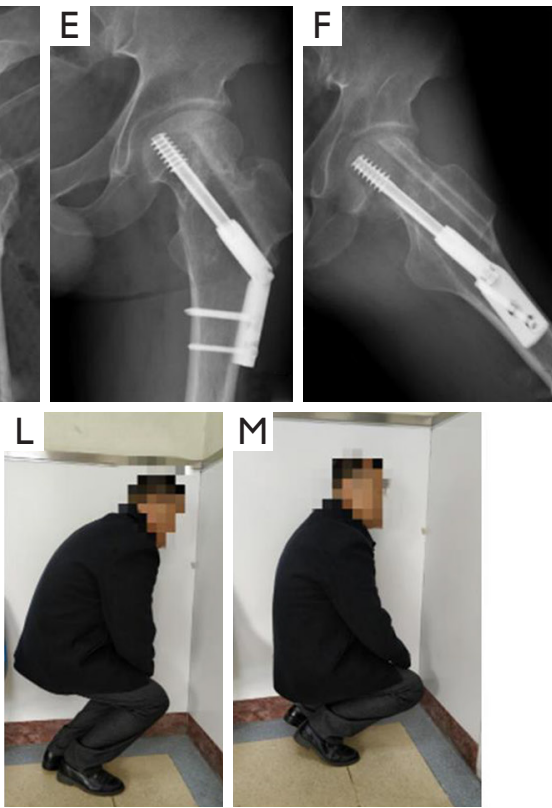

Figure 2 A 40-year-old male patient with left femoral neck fracture was treated with DHS combined with fibula bone grafting. (A,B) Preoperative positive and lateral X-ray of the hip joint showed a fracture of the left femoral neck; (C,D) postoperative positive and lateral $\mathrm{X}$-ray of the hip joint showed the internal fixator was present; (E,F) 6 months after the operation, positive and lateral X-ray of the hip joint showed that the fracture had healed and the internal fixation was present and good; $(\mathrm{G}, \mathrm{H}) 14$ months after the operation, positive and lateral X-ray of the hip joint showed that the fracture had healed and the internal fixation was present and good; (I,J) 14 months after the operation, positive and lateral X-ray of the hip joint showed that the fracture had healed and the internal fixation was removed. Then the fibula implant is in a good position and does not break; $(\mathrm{K}, \mathrm{L}, \mathrm{M})$ the general image before removal of the internal fixator showed no shortening of the affected limb and no obstruction of squat.

rate of nail withdrawal rate, fracture nonunion and femoral head necrosis for DHS with fibula graft was significantly lower than that of DHS with CS. The possible reasons were the implanted fibula compensates for the defect in the posterior wall, enhances the stability of fracture ends, provides a good healing environment, and reduces the rate of nonunion and necrosis. As a cortical bone, fibula can not only provide mechanical strength and supports for internal fixation, but also compensate for the defect in the posterior wall and further increase the stability of fracture end. Furthermore, the three-sided shape of fibula can increase anti-rotation stability, providing a good foundation for the femoral head revascularization (34-36).

The limitation of this study was that reduction was difficult due to fracture dislocation in some patients. Even closed reduction cannot reach the ideal state and head and neck stem interactive reduction or limited incision reduction was required. In addition, some patients underwent displacement again during closed reduction, which further increased the operation time. Therefore, we will emphasize that two Kirschner wires should be used to fix the acetabulum to stabilize the fracture after the closed reduction in our further work.

In conclusion, compared to patients treated with the DHS combined with CS, DHS combined with fibula graft in young adults Pauwels type III femoral neck fracture has a high Harris function score, better bone healing and lower complications of femoral head necrosis with good the hip joint function outcomes. Further studies are warranted.

\section{Acknowledgments}

Funding: This work was supported by Qinghai Provincial Science and Technology Department launches basic research project (No: 2019-ZJ-7095).

\section{Footnote}

Reporting Checklist: The authors have completed the STROBE reporting checklist. Available at http://dx.doi. 
org/10.21037/atm-19-3344

Data Sharing Statement: available at http://dx.doi. org/10.21037/atm-19-3344

Conflicts of Interest: All authors have completed the ICMJE uniform disclosure form (available at http://dx.doi. org/10.21037/atm-19-3344). The authors have no conflicts of interest to declare.

Ethical Statement: All authors are accountable for all aspects of the work in ensuring that questions related to the accuracy or integrity of any part of the work are appropriately investigated and resolved. This study was approved by the Medicine Human Experimental ethic committee of Qinghai University School.

Open Access Statement: This is an Open Access article distributed in accordance with the Creative Commons Attribution-NonCommercial-NoDerivs 4.0 International License (CC BY-NC-ND 4.0), which permits the noncommercial replication and distribution of the article with the strict proviso that no changes or edits are made and the original work is properly cited (including links to both the formal publication through the relevant DOI and the license). See: https://creativecommons.org/licenses/by-nc-nd/4.0/.

\section{References}

1. Khong TP, de Vries F, Goldenberg JS, et al. Potential impact of benzodiazepine use on the rate of hip fractures in five large European countries and the United States. Calcif Tissue Int 2012;91:24-31.

2. Xu JL, Liang ZR, Xiong BL, et al. Risk factors associated with osteonecrosis of femoral head after internal fixation of femoral neck fracture: a systematic review and metaanalysis. BMC Musculoskelet Disord 2019;20:632 .

3. Elgeidi A, El-Negery A. Fibular strut graft for nonunited femoral neck fractures in children. J Child Orthop 2017;11:28-35.

4. Sun Q, Li G, Ge W, et al. Effectiveness analysis of surgical treatment of ipsilateral femoral neck fracture and subtrochanteric fracture. Zhongguo Xiu Fu Chong Jian Wai Ke Za Zhi 2017;31:1043-8.

5. Bartonícek J. Pauwels' classification of femoral neck fractures: correct interpretation of the original. J Orthop Trauma 2001;15:358-60.

6. Gjertsen J-E, Vinje T, Engesaeter L, et al. Internal screw fixation compared with bipolar hemiarthroplasty for treatment of displaced femoral neck fractures in elderly patients. J Bone Joint Surg Am 2010;92:619-28.

7. Gurusamy K, Parker M, Rowlands T. The complications of displaced intracapsular fractures of the hip: the effect of screw positioning and angulation on fracture healing. J Bone Joint Surg Br 2005;87:632-4.

8. Eid A. Valgus osteotomy for delayed presentation of femoral neck fractures Pauwels Grade III. J Orthop Trauma 2010;24:115-9.

9. Waaler Bjørnelv GM, Frihagen F, Madsen J, et al. Hemiarthroplasty compared to internal fixation with percutaneous cannulated screws as treatment of displaced femoral neck fractures in the elderly: cost-utility analysis performed alongside a randomized, controlled trial. Osteoporos Int 2012;23:1711-9.

10. van Embden D, Roukema G, Rhemrev SJ, et al. The Pauwels classification for intracapsular hip fractures: is it reliable? Injury 2011;42:1238-40.

11. Davidovitch RI, Jordan CJ, Egol KA, et al. Challenges in the treatment of femoral neck fractures in the nonelderly adult. J Trauma 2010;68:236-42.

12. Pauwels F. Der Schenkelhalsbruch ein mechanisches Problem: Grundlagen d. Heilungsvorganges, Prognose u kausale Therapie Ferdinand Enke Stuttgart 1935.

13. Leadbetter GW. Closed reduction of fractures of the neck of the femur. J Bone Joint Surg 1938;20:309-17.

14. McELVENNY RT. The immediate treatment of intracapsular hip fracture. Clin Orthop 1957;10:289-325.

15. Zhang C, Wang Q, Qiu G, et al. Three-dimensional interactive reduction of femoral neck and shaft for treatment of irreducible femoral neck fracture. Chinese Journal of Trauma 2014;30:217-20.

16. Singh S, Kumar D, Kumar S. Long term results of fresh femoral neck fractures treated by cancellous screw and fibular autograft. MOJ Orthop Rheumatol 2014;1:00020.

17. Zhang Y, Liu Y, Zhou G, et al. Fibular allograft for osteonecrosis prevention in the management of femoral neck fractures: clinical outcome and biomechanical evaluation. J Biomaterials Tissue Engineering 2015;5:937-41.

18. Takigawa N, Yasui K, Eshiro H, et al. Clinical results of surgical treatment for femoral neck fractures with the Targon((R)) FN. Injury 2016;47 Suppl 7:S44-8.

19. Windolf $M$, Braunstein V, Dutoit C, et al. Is a helical shaped implant a superior alternative to the Dynamic Hip Screw for unstable femoral neck fractures? A biomechanical investigation. Clin Biomech (Bristol, Avon) 


\section{Page 8 of 8}

2009;24:59-64.

20. Bonnaire FA, Weber A. Analysis of fracture gap changes, dynamic and static stability of different osteosynthetic procedures in the femoral neck. Injury 2002;33:C24-32.

21. Li G, Jin D, Shao X, et al. Effect of cannulated screws with deep circumflex iliac artery-bone grafting in the treatment of femoral neck fracture in young adults. Injury 2018;49:1587-93.

22. Makki D, Mohamed AM, Gadiyar R, et al. Addition of an anti-rotation screw to the dynamic hip screw for femoral neck fractures. Orthopedics 2013;36:e865-8.

23. Zahid M, Sabir AB, Asif N, et al. Fixation using cannulated screws and fibular strut grafts for fresh femoral neck fractures with posterior comminution. J Orthop Surg (Hong Kong) 2012;20:191-5.

24. Banks HH. Factors influencing the result in fractures of the femoral neck. JBJS 1962;44:931-64.

25. Kunapuli SC, Schramski MJ, Lee AS, et al. Biomechanical analysis of augmented plate fixation for the treatment of vertical shear femoral neck fractures. J Orthop Trauma 2015;29:144-50.

26. Inclan A. Late complications in fracture of the neck of the femur treated by nailing, bone grafting or both. J Int Coll Surg 1946;9:36-50.

27. Banaszkiewicz PA. Traumatic arthritis of the hip after dislocation and acetabular fractures: treatment by mold arthroplasty: an end-result study using a new method of result evaluation. Classic Papers in Orthopaedics. Springer, 2014:13-7.

28. Mathews V, Cabanela ME. Femoral neck nonunion treatment. Clin Orthop Relat Res 2004;419:57-64.

Cite this article as: Li Z, Zhang $\mathrm{X}, \mathrm{Li}$ Z, Peng A, Zhang L, Deng Y, Song L. Comparative study of Pauwels type III femoral neck fractures managed by short dynamic hip screw with fibula bone graft or cannulated screws in young adults. Ann Transl Med 2020;8(11):681. doi: 10.21037/atm-19-3344

\section{Li et al. Comparative study of Pauwels type III femoral neck fractures}

29. LeCroy CM, Rizzo M, Gunneson EE, et al. Free vascularized fibular bone grafting in the management of femoral neck nonunion in patients younger than fifty years. J Orthop Trauma 2002;16:464-72.

30. Nagi ON, Gautam V, Marya S. Treatment of femoral neck fractures with a cancellous screw and fibular graft. J Bone Joint Surg Br 1986;68:387-91.

31. Gadegone WM, Chandak RM, Lokhande VR. DHS osteosynthesis with internal bone grafting in unstable delayed presented intracapsular neck femur fractures. Injury 2017;48 Suppl 2:S44-9.

32. Elgeidi A, El Negery A, Abdellatif MS, et al. Dynamic hip screw and fibular strut graft for fixation of fresh femoral neck fracture with posterior comminution. Arch Orthop Trauma Surg 2017;137:1363-9.

33. Tripathy SK, Sen RK, Goyal T. Nonvascularized fibular grafting in nonunion of femoral neck fracture: A systematic review. Indian J Orthop 2016;50:345-51.

34. Khani GMK, Hafeez K, Bux M, et al. Use of fibular bone graft and cancellous screw fixation in the management of neglected femur neck fractures in young patients. Int $\mathrm{J}$ Health Sci (Qassim) 2017;11:7.

35. Nagi ON, Dhillon MS, Goni VG. Open reduction, internal fixation and fibular autografting for neglected fracture of the femoral neck. J Bone Joint Surg Br 1998;80:798-804.

36. Jaiswal A, Pruthi K, Goyal R, et al. Evaluation of osteosynthesis with dual fibular bone grafting for neglected femoral neck fractures. J Clin Orthop Trauma 2013;4:58-69. 